\title{
Self-microemulsifying drug-delivery system for improved oral bioavailability of probucol: preparation and evaluation
}

This article was published in the following Dove Press journal:

International Journal of Nanomedicine

9 February 2012

Number of times this article has been viewed

\author{
Xianyi Sha \\ Juan Wu \\ Yanzuo Chen \\ Xiaoling Fang \\ Key Laboratory of Smart Drug \\ Delivery (Fudan University), Ministry \\ of Education and PLA, Department \\ of Pharmaceutics, School of Pharmacy, \\ Fudan University, Shanghai, China
}

\begin{abstract}
The objective of our investigation was to design a self-microemulsifying drug-delivery system (SMEDDS) to improve the bioavailability of probucol. SMEDDS was composed of probucol, olive oil, Lauroglycol FCC, Cremophor EL, Tween-80, and PEG-400. Droplet sizes were determined. In vitro release was investigated. Pharmacokinetics and bioavailability of probucol suspension, oil solution, and SMEDDS were evaluated and compared in rats. Plasma drug concentration was determined by high-performance liquid chromatography. After administration of probucol suspension, plasma drug concentration was very low. Relative bioavailability of SMEDDS was dramatically enhanced in an average of 2.15- and 10.22-fold that of oil solution and suspension, respectively. It was concluded that bioavailability of probucol was enhanced greatly by SMEDDS. Improved solubility and lymphatic transport may contribute to the enhancement of bioavailability.
\end{abstract}

Keywords: self-microemulsifying drug-delivery system (SMEDDS), probucol, bioavailability

\section{Introduction}

Probucol, a chemical compound with a bisphenol structure, was originally synthesized as an antioxidant by Consolidation Coal Company and screened at Dow Chemical Company for its ability to reduce serum cholesterol. ${ }^{1}$ Probucol has been used widely in clinical practice for the prevention of the progression of atherosclerosis because this agent acts as a potent antioxidant in addition to having a lipid-lowering action. ${ }^{2}$ In addition, probucol can stop progression of atherosclerotic plaques in carotid arteries. ${ }^{3}$

However, probucol is slightly absorbed in the gastrointestinal tract due to its poor solubility in water (the $\log \mathrm{P}$ was reported to be 10.91). ${ }^{4}$ The oral bioavailability of probucol is very low. From studies in rats, dogs, and monkeys, it is known that probucol accumulates slowly in adipose tissue. Approximately $90 \%$ of probucol administered orally is unabsorbed. ${ }^{5}$

Research has been focused on enhancing the solubility of poorly water-soluble drugs to improve their oral bioavailability. One of the most popular approaches is lipidbased formulation, such as oils, surfactant dispersions, self-emulsifying formulations, emulsions, and liposomes. ${ }^{6}$

Self-microemulsifying drug-delivery systems are mixtures of drugs, lipids, surfactants, and cosurfactants, which form a fine oil-in-water $(\mathrm{O} / \mathrm{W})$ microemulsion with a droplet size of less than $100 \mathrm{~nm}$ when exposed to aqueous media under conditions of gentle agitation or digestive motility that would be encountered in the gastrointestinal (GI) tract. SMEDDS has recently emerged as one of the most interesting approaches to improve oral absorption for poorly water-soluble drugs. ${ }^{7,8}$ The advantages of SMEDDS
Correspondence: Xiaoling Fang

826 Zhangheng Road,

Shanghai 201203, China

Tel $+86215198007 \mid$

Fax +86 21 51980071

Email xlfang@shmu.edu.cn 
include ease of production, enhanced solvent capacity, increased stability, and the potential to administer the final product as an oral soft gelatin cap. ${ }^{9}$ The commercially available formulation cyclosporine $\left(\mathrm{Neoral}^{\mathrm{TM}}\right)$ is a microemulsion preconcentrate with improved oral bioavailability and reduced inter- and intra-subject variability compared to the original crude emulsion product, Sandimmune ${ }^{\mathrm{TM}} .{ }^{10}$ Similar lipid-based formulations of the human immunodeficiency virus (HIV) protease inhibitors, saquinavir, ritonavir, and amprenavir, have also reached the market. ${ }^{6}$ To date, probucol formulated in SMEDDS has not yet been evaluated.

The objectives of our present study were to prepare, and characterize a SMEDDS formulation of probucol, and assess its oral absorption in rats.

\section{Materials and methods Materials}

Probucol was purchased from Qihe Jinzhun Technology Co, Ltd, (Shandong, China). Olive oil, PEG-400, Tween-80, and N-hexane were purchased from Sinopharm Chemical Reagent Co, Ltd, (Shanghai, China). Lauroglycol FCC was kindly donated by Gattefosse S.A (Saint-Priest, France). Cremophor EL was kindly provided by BASF Corp. (Washington, NJ). Retinyl acetate was purchased from Sigma Chemical Co. (St Louis, MO). Acetonitrile (high-pressure liquid chromatography [HPLC] grade) was supplied by Burdick and Jackson Corp. (Muskegon, MI). Deionized water was prepared by an Aquapro purification system (Chongqing Yiyang Co Ltd, Chongqin, China). All other chemicals were analytical grade.

\section{Animals}

Male Sprague-Dawley (SD) rats $(230 \pm 20 \mathrm{~g})$ and imprinting control region (ICR) mice (20 $\pm 2 \mathrm{~g}$ ), supplied by Department of Experimental Animals, Fudan University (Shanghai, China), were acclimated at $25^{\circ} \mathrm{C}$ and $55 \%$ of humidity under natural light/dark conditions for 1 week before the experiment. All animal experiments were carried out in accordance with guidelines evaluated and approved by the ethics committee of Fudan University.

\section{Preparation of SMEDDS formulations}

Probucol SMEDDS was composed of olive oil (13\%, w/w), Lauroglycol FCC (27\%, w/w), Cremophor EL (20\%, w/w), Tween-80 (20\%, w/w), and PEG-400 (20\%, w/w). Preparation of probucol SMEDDS was simply by mixing the components. Since probucol was difficult to dissolve, it was better to dissolve probucol first in Lauroglycol FCC. Olive oil, Cremophor EL, and PEG-400 were then added slowly with gentle stirring until a homogeneous mixture formed. The mixture was sealed in a glass vial and stored under room temperature.

\section{Droplet size}

One gram of SMDROPLET SIZEEDDS was diluted in $250 \mathrm{~mL}$ of deionized water, phosphate-buffered saline (PBS; $\mathrm{pH}$ 7.0), and 0.1 M hydrochloride solution, respectively. The solution was inverted and shaken gently to mix thoroughly. The droplet size of microemulsion was determined by Nicomp $^{\text {TM }} 380$ ZLS laser diffraction sizer (PSS Nicomp, Santa Barbara, CA). The measurement conditions were: $\mathrm{He}-\mathrm{Ne}$ laser; angle, $90^{\circ}$; temperature, $23^{\circ} \mathrm{C}$; reflection index, 1.333; wavelength, $632.8 \mathrm{~nm}$; or with adjustment if needed.

In order to determine the effects of different media and dilution volume on the droplet size of microemulsion, $1 \mathrm{~g}$ of SMEDDS was added into $10 \mathrm{~mL}, 20 \mathrm{~mL}, 50 \mathrm{~mL}, 100 \mathrm{~mL}$, $250 \mathrm{~mL}$, and $500 \mathrm{~mL}$ of deionized water, PBS (pH 7.0), and $0.1 \mathrm{M}$ hydrochloride solution, respectively, and the resulting solutions were slightly shaken. The droplet sizes of these solutions were analyzed.

The effect of drug loading on droplet size in different media was studied. Five milligrams, $10 \mathrm{mg}, 20 \mathrm{mg}, 40 \mathrm{mg}$, and $60 \mathrm{mg}$ of probucol were added to $1 \mathrm{~g}$ of blank SMEDDS. These probucol-loading SMEDDS were diluted to $250 \mathrm{~mL}$ deionized water, PBS ( $\mathrm{pH} 7.0$ ), and 0.1 M hydrochloride solution, respectively, and the droplet sizes of resulted solutions were determined.

\section{Morphology}

The morphology of SMEDDS was observed using a transmission electron microscope (TEM; CM120; Philips Co, Amsterdam, The Netherlands). SMEDDS was diluted with deionized water at 1:50 and mixed by slight shaking. One drop of diluted samples was deposited on a film-coated copper grid and then stained with one drop of $2 \%$ aqueous solution of phosphotungstic acid (PTA), and allowed to dry before observation under the electron microscope.

\section{Dissolution studies}

In order to compare the dissolution behaviors of probucol-loaded SMEDDS and crude probucol, PBS ( $\mathrm{pH} 7.0$ ) and 0.1 M hydrochloride solution were chosen as the dissolution media. Dissolution studies were performed according to the method described previously. ${ }^{11}$

SMEDDS containing $60 \mathrm{mg}$ of probucol or $60 \mathrm{mg}$ of crude probucol was filled in hard gelatin capsules and introduced 
into $200 \mathrm{~mL}$ of a dissolution medium maintained at $37^{\circ} \mathrm{C}$. The revolution speed of the paddle was kept constant at $100 \mathrm{rpm}$. Aliquot of $5 \mathrm{~mL}$ was withdrawn at $0,10,20,30,40$ and 60 minutes, and filtered through $0.45 \mu \mathrm{m}$ membrane filters. The concentration of probucol was determined by HPLC. The removed volume was replaced each time with $5 \mathrm{~mL}$ of fresh medium.

\section{Bioavailability study}

Bioavailability of probucol SMEDDS was compared with probucol suspension and olive oil solution. Rats were fasted overnight before experiment with free access to water. Probucol suspension (probucol dispersed in $1 \%[\mathrm{w} / \mathrm{v}]$ carboxymethyl cellulose-Na solution), probucol dissolved in olive oil and probucol-loaded SMEDDS (60 mg/kg of body weight) were given to the rats by intragastric administration, respectively. About $0.8 \mathrm{~mL}$ of blood sample was collected into heparinized tubes at $0.5,1,2,4,5,6,8,12,24,48,96$, and 120 hours. Blood samples were centrifuged at 10,000 rpm for 10 minutes and plasma samples were collected and stored at $-18^{\circ} \mathrm{C}$.

\section{Determination of probucol in rat plasma by RP-HPLC}

All samples were analyzed by a modified HPLC/UV method. The HPLC system consisted of a LC-10AT pump, a SPD-10A UV detector (Shimadzu, Kyoto, Japan), and a data-processing system (N2000, YingPu Co Ltd, Hangzhou, China). Probucol was separated by a $\mathrm{C}_{18}$ column $(5 \mu \mathrm{m}, 4.6 \mathrm{~mm} \times 150 \mathrm{~mm}$; Phenomenex, Torrance, CA) guarded with a refillable precolumn $\left(\mathrm{C}_{18}, 2.0 \mathrm{~mm} \times 20 \mathrm{~mm}\right.$; Phenomenex, Torrance, $\left.\mathrm{CA}\right)$ at room temperature. Probucol was detected at $242 \mathrm{~nm}$. The mobile phase was a mixture of acetonitrile: $\mathrm{H}_{2} \mathrm{O}(96: 4, \mathrm{v} / \mathrm{v})$ and was delivered at a flow rate of $1 \mathrm{~mL} \cdot$ minute $^{-1}{ }^{12}$

Liquid-liquid plasma extraction procedure was used as follows: in a $5 \mathrm{~mL}$ tube, $300 \mu \mathrm{L}$ plasma was added, followed by $10 \mu \mathrm{L}$ of internal standard $\left(50 \mu \mathrm{g} \cdot \mathrm{mL}^{-1}\right.$ of retinyl acetate $)$ solution, and vortex mixed for 30 seconds. Then $150 \mu \mathrm{L}$ of ethanol and $200 \mu \mathrm{L}$ of methanol were added to precipitate the protein. Then $1 \mathrm{~mL}$ of hexane was added and vortexed for 3 minutes. After centrifuging at 12,000 rpm for 10 minutes, the upper layer was transferred to another tube and evaporated under a light stream of nitrogen at $40^{\circ} \mathrm{C}$. The residue was dissolved by $100 \mu \mathrm{L}$ of mobile phase and $20 \mu \mathrm{L}$ was injected for HPLC analysis. Quantification was based on area ratio of probucol and the internal standard. ${ }^{13}$

The retention times for internal standard and probucol were about 6.7 minutes and 11.0 minutes, respectively.
The linearity was obtained in the range from 0.05 to $30 \mu \mathrm{g} \cdot \mathrm{mL}^{-1}$. The coefficient of variation for intra- and interday assays was less than $5 \%$. The average recovery of probucol from plasma was between $98.6 \%$ and $101.4 \%$.

\section{Data analysis}

The pharmacokinetics' parameters were calculated by DAS 2.0 (issued by the State Food and Drug Administration of China for Pharmokinetic Study). Student's $t$-tests were performed to evaluate the significant differences. Values are reported as Mean \pm standard deviation, and the data were considered statistically significant at $P<0.05$.

\section{Results and discussion SMEDDS formulation}

In our pseudoternary phase diagram study (Figure 1), systems consisting of olive oil and Lauroglycol FCC as oil phase, Cremophor EL and Tween-80 as emulsifiers, and PEG-400 as coemulsifier were titrated with water, and self-emulsifying formulations were selected from regions undergoing infinite dilution. In the diagrams (Figure 1A-D), with the decrease of olive oil/Lauroglycol FCC ratio, the area of self-microemulsifying region increased. When the Cremophor EL/Tween-80 ratio increased, the area of self-microemulsifying region increased (Figure 1D and E). Diagrams with higher emulsifier/co-emulsifier ratio had larger self-microemulsifying area (Figure 1D, F, G). The optimal formulation of probucol SMEDDS was selected to investigate the self-microemulsifying ability, solubilization ability, and reduced use of emulsifiers, was as follows: olive oil (13\%, w/w), Lauroglycol FCC (27\%, w/w), Cremophor EL (20\%, w/w), Tween-80 (20\%, w/w), and PEG-400 (20\%, w/w). Sixty milligrams of probucol was dissolved in $1 \mathrm{~g}$ of mixture.

\section{Droplet size}

Droplet size after microemulsification was the most important property of SMEDDS. It may affect the release and absorption of drug in GI tract. ${ }^{14,15}$ The typical size distribution is shown in Figure 2. It seemed that dilution volume within the investigated range and different dilution media had little effect on droplet size (Figure 3 ) and selfmicroemulsifying behavior $(P>0.05)$. The mean droplet size did not change significantly with increased drug loading (Figure $4 ; P>0.05$ ).

\section{Morphology}

Morphology of the microemulsions formed from SMEDDS was viewed under a TEM, the microemulsion vesicles 

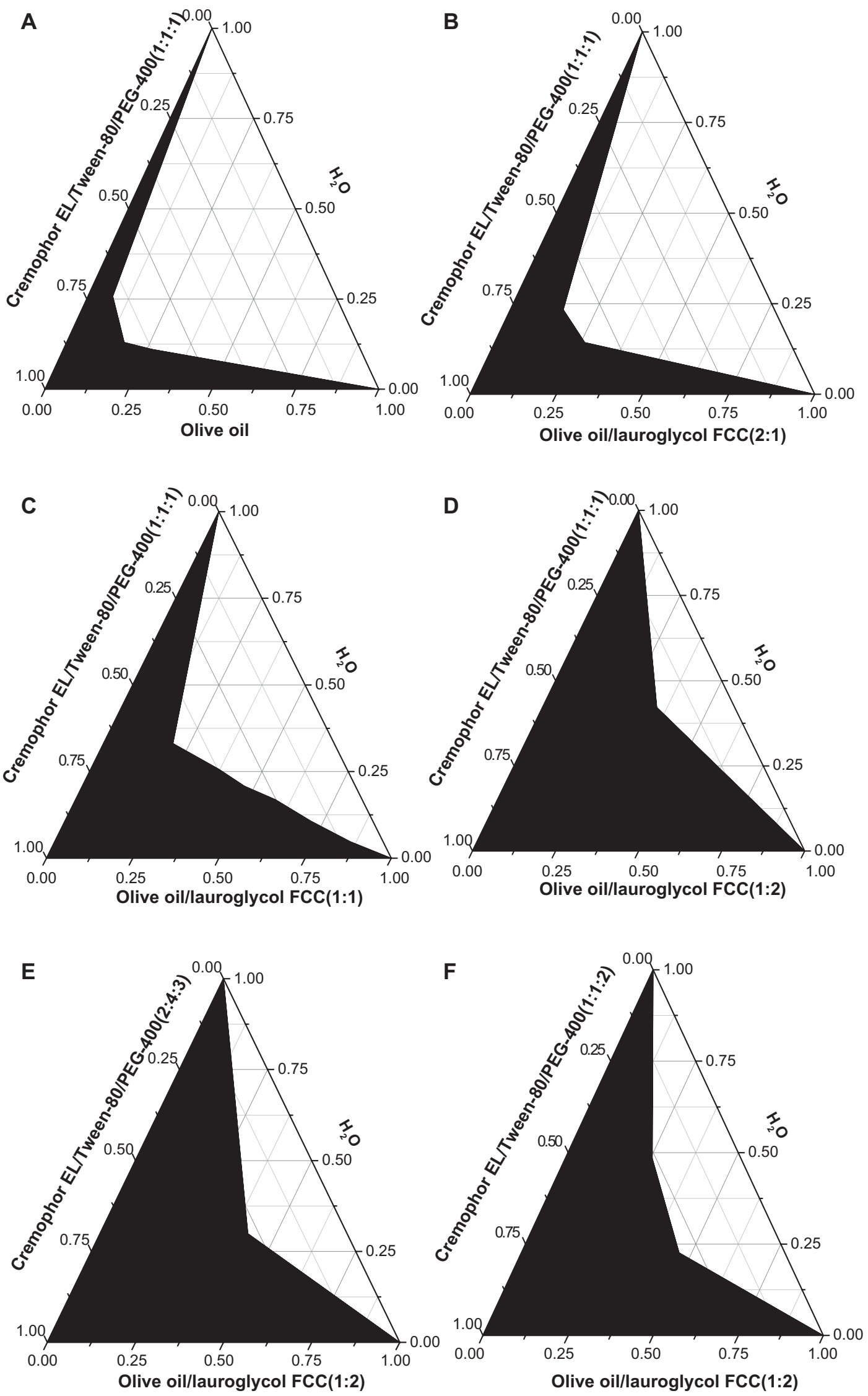

Figure I (Continued) 


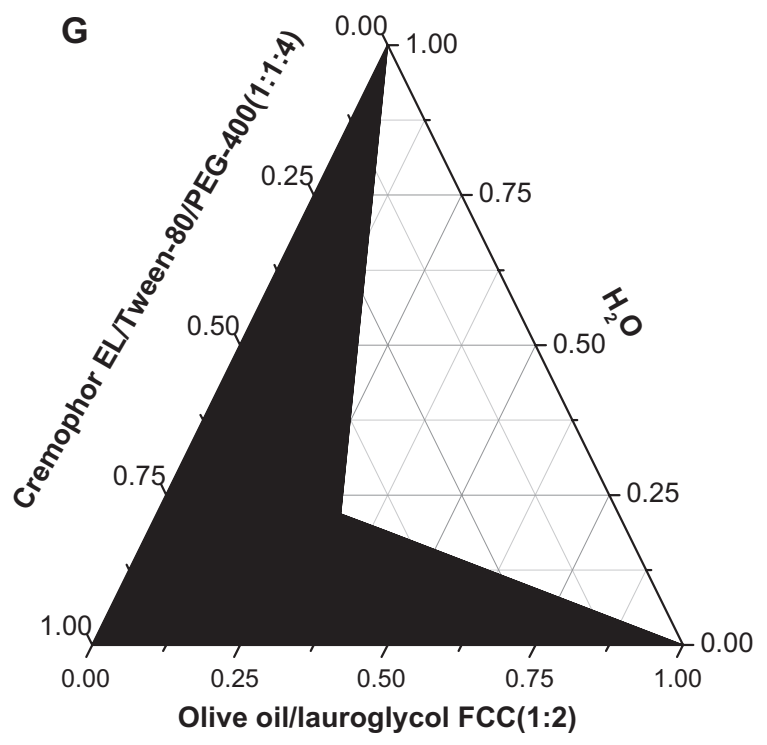

Figure I Pseudoternary phase diagrams of different composition of oil phase, emulsifiers, and coemulsifiers.

Note: The dark regions represent the microemulsion phase.

appeared as perfect round shapes without aggregation (Figure 5).

\section{Dissolution studies}

Our previous study showed probucol was practically insoluble in water at acidic or neutral $\mathrm{pH}$. As shown in Figure 6, crude probucol showed negligible release even after 60 minutes in both PBS ( $\mathrm{pH}$ 7.0) and 0.1 M hydrochloride solution. Whereas, SMEDDS showed rapid dissolution in both solutions, at 10 minute about $80 \%$ of probucol from SMEDDS was dissolved in medium, and more than $90 \%$ was released after 20 minutes. SMEDDS could form clear and transparent solution in the condition of dissolution quickly.

\section{Bioavailability study}

The pharmacokinetic parameters of probucol SMEDDS, oil solution, and suspension were compared in rats. Mean plasma probucol concentration was plotted as a function of time (Figure 7).

The pharmacokinetic parameters of SMEDDS, oil solution, and suspension are shown in Table 1. As can be seen, the maximum concentration $\left(\mathrm{C}_{\max }\right)$ of probucol SMEDDS was $3.36 \pm 0.84 \mu \mathrm{g} \cdot \mathrm{mL}^{-1}$, compared with those of oil solution and suspension which were $1.80 \pm 0.43 \mu \mathrm{g} \cdot \mathrm{mL}^{-1}$ and $0.16 \pm 0.07 \mu \mathrm{g} \cdot \mathrm{mL}^{-1}$, respectively. Statistically, the differences in $\mathrm{C}_{\max }$ of probucol SMEDDS were extremely significant $(P<0.01)$ when compared with $\mathrm{C}_{\max }$ of oil solution

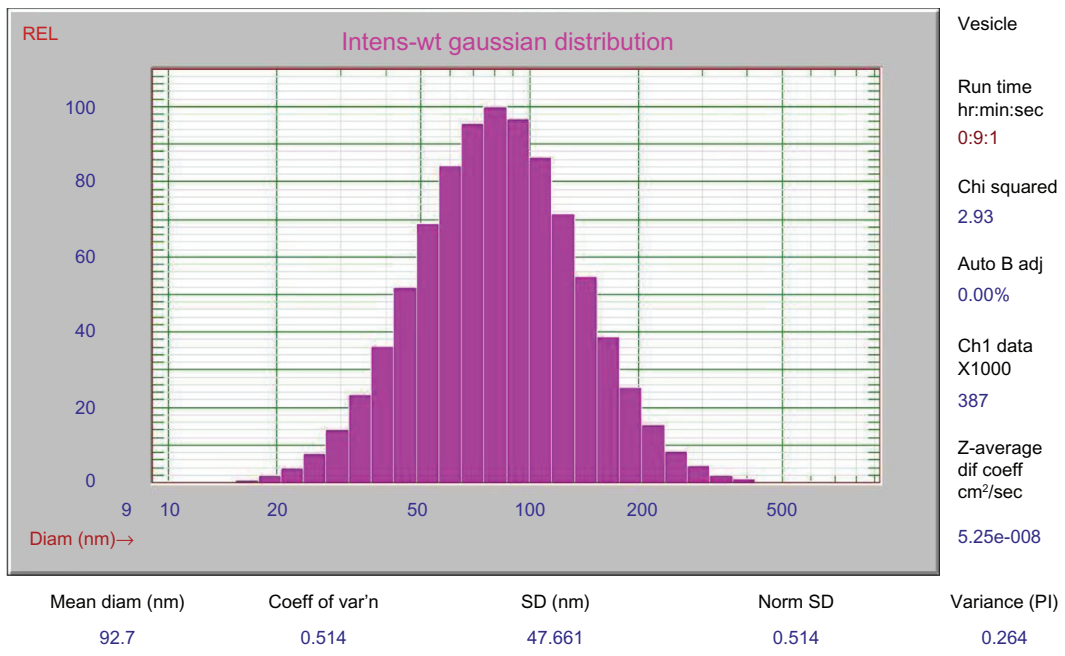

Figure 2 Size distribution of probucol self-microemulsifying drug-delivery system determined by laser diffraction sizer after dilution to deionized water. Abbreviations: REL, relative; Intens-wt, intensive weight; Auto B adj, automatic B adjust; Ch I data, channel I data; Z-average diff coeff, Z-average difference coefficient; PI, polydispersity index; Coeff of var'n, coefficient of variance; SD, standard deviation. 


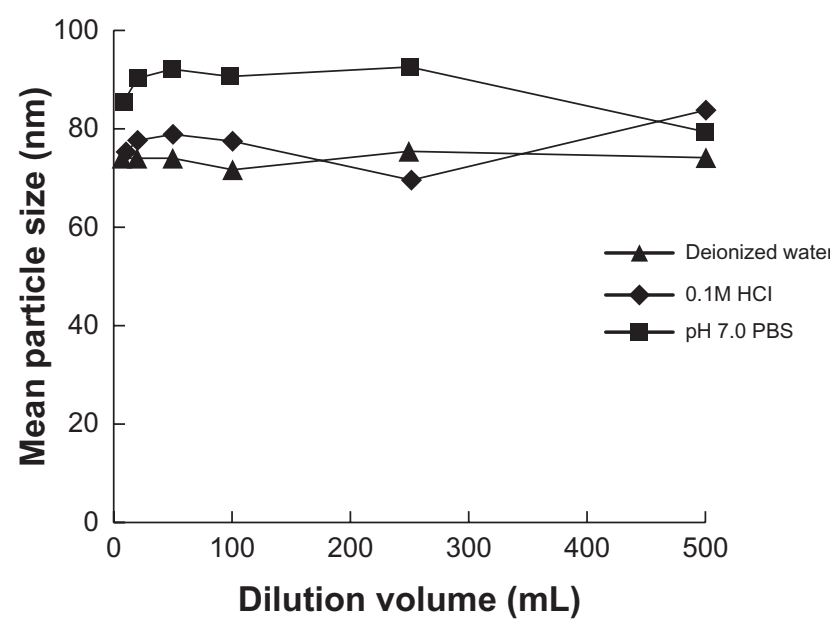

Figure 3 Effects of dilution media and dilution volume on droplet size of probucol self-microemulsifying drug-delivery system $(P>0.05)$.

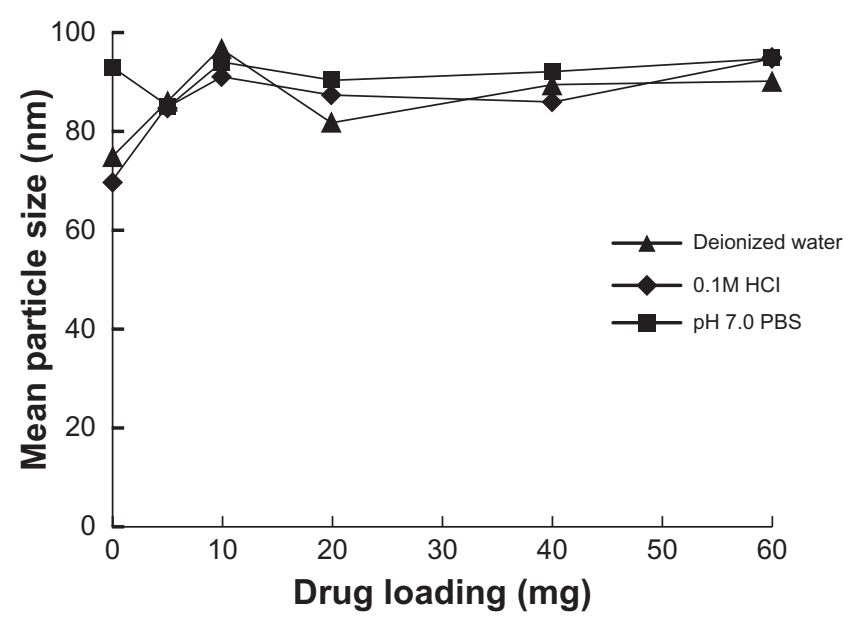

Figure 4 Effects of drug loading on droplet size of probucol SMEDDS in different media $(P>0.05)$.

Abbreviations: PBS, phosphate-buffered saline; SMEDDS, self-microemulsifying drug-delivery system.

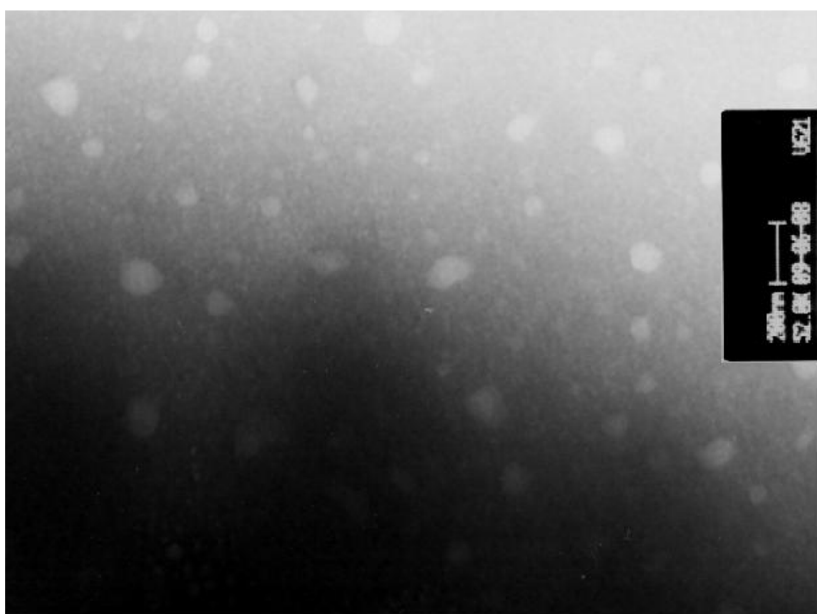

Figure 5 Transmission electron microscopy of probucol microemulsion at the dilution of $1: 50$ in deionized water.

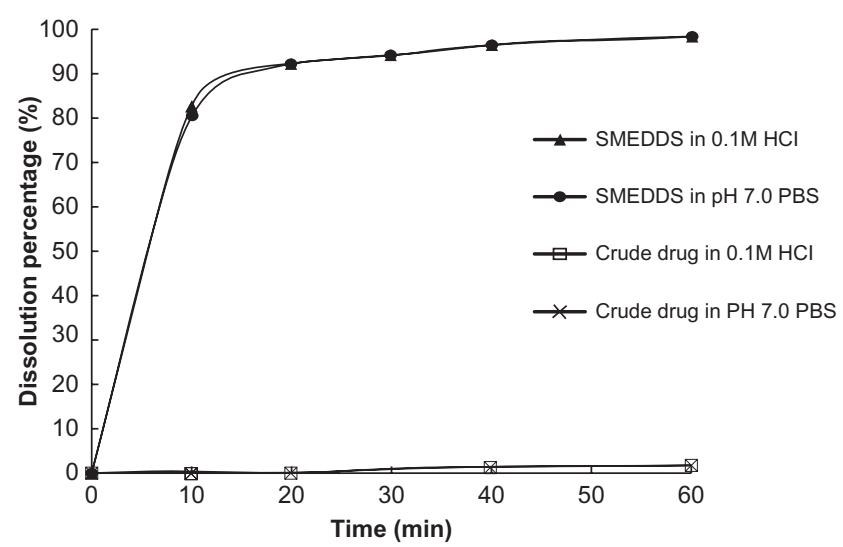

Figure 6 Dissolution profiles of probucol SMEDDS and crude drug in $0.1 \mathrm{M} \mathrm{HCl}$ or in $\mathrm{pH} 7.0$ PBS.

Note: Each value represents the mean $\pm \operatorname{SD}(n=3)$.

Abbreviations: PBS, phosphate-buffered saline; SD, standard deviation; SMEDDS, self-microemulsifying drug-delivery system.

$(P<0.01)$ and suspension $(P<0.001)$. It was also observed that the area under the curve $\left(\mathrm{AUC}_{0-120 \text { hours }}\right)$ of SMEDDS was $73.59 \pm 31.21 \mu \mathrm{g} \cdot \mathrm{mL}^{-1} \cdot$ hour, and thus the difference was highly significant compared with that of the oil solution ( $34.16 \pm 10.65 \mu \mathrm{g} \cdot \mathrm{mL}^{-1} \cdot$ hour $)(P<0.02)$ and suspension $\left(7.20 \pm 1.63 \mu \mathrm{g} \cdot \mathrm{mL}^{-1} \cdot\right.$ hour $)(P<0.001)$. The bioavailability of SMEDDS was 2.15- and 10.22-fold that of oil solution and suspension, respectively.

Lipid-based formulations such as oil solution and selfmicroemulsifying drug-delivery systems offer the potential for enhancing the absorption and hence the oral bioavailability of lipophilic drugs. The primary mechanisms are presenting the drug in solubilized form in vivo, delaying gastric emptying, increasing mucosal permeability, and increasing incorporation into lipoproteins, then secreted into the lymphatics, which circumvents the liver, thus reducing the hepatic first-pass metabolism. ${ }^{14,16-18}$

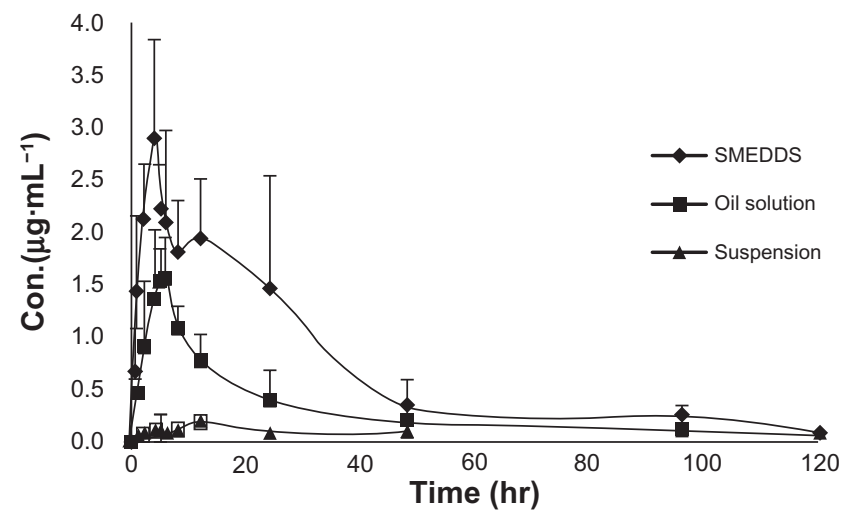

Figure 7 Plasma probucol concentration-time plot after a single oral dose of probucol in three formulations.

Note: Each value represents the mean \pm SD $(n=6)$.

Abbreviations: SD, standard deviation; SMEDDS, self-microemulsifying drugdelivery system. 
Table I Pharmacokinetic parameters of probucol in three formulations

\begin{tabular}{lccc}
\hline Parameter & SMEDDS & Oil solution & Suspension \\
\hline $\mathrm{t}_{\max }($ hours $)$ & $4.33 \pm 0.82$ & $5.17 \pm 0.98$ & $14.83 \pm 7.60$ \\
$\mathrm{C}_{\max }\left(\mu \mathrm{g} \cdot \mathrm{mL}^{-1}\right)$ & $3.36 \pm 0.84$ & $1.80 \pm 0.43^{* *}$ & $0.16 \pm 0.07^{* * *}$ \\
$\mathrm{Ka}\left(\mathrm{hour}^{-1}\right)$ & $0.84 \pm 0.87$ & $0.52 \pm 0.33$ & $0.21 \pm 0.31$ \\
$\mathrm{AUC}_{0-120 \text { hours }}\left(\mu \mathrm{g} \cdot \mathrm{mL}^{-1} \cdot\right.$ hour $)$ & $73.59 \pm 31.21$ & $34.16 \pm 10.65^{*}$ & $7.20 \pm 1.63^{* * *}$ \\
$\mathrm{AUC}_{0-\perp}\left(\mu \mathrm{g} \cdot \mathrm{mL}^{-1} \cdot\right.$ hour$)$ & $78.69 \pm 34.13$ & $37.98 \pm 12.69$ & $9.35 \pm 1.85$ \\
\hline
\end{tabular}

Notes: $* P<0.02 ; * * P<0.01$; $* * * P<0.001$; when compared with those of probucol SMEDDS by Student's $t$-test. Each value represents the mean \pm SD ( $\mathrm{n}=6$ )

Abbreviation: SMEDDS, self-microemulsifying drug-delivery system.

It was reported that probucol had high lymphatic bioavailability when coadministrated with lipids. ${ }^{19,20}$ Chylomicrons (CMs) are important in drug delivery since many lipophilic drugs are carried by CMs and transported in lymph. ${ }^{21}$ Palin and Wilson reported that digestion of oil within the small intestine resulted in the liberation of long-chain fatty acids, which effectively promoted chylomicron formation and consequently the lymphatic transport of DDT or probucol. ${ }^{19}$

Enhancement of bioavailability of probucol SMEDDS compared with oil solution may be due to effects of a large quantity of surfactants and cosurfactant, including improved mucosal permeability, smaller lipid droplets and greater surface area. In addition, it was reported that Tween- 80 can promote $\mathrm{CMs}$ secretion and counteracted the inhibitory effects of other surfactants. ${ }^{22}$

Double peaks of $\mathrm{C}_{\max }$ were observed after administration of SMEDDS. This may be caused by protection effects of surfactants for lipid from digestion, high lymphatic bioavailability of probucol, and the slow flow rate of lymph. It has been proven that the presence of digestion products such as monoglycerides and fatty acids, incorporated in bile salt micelles, increases the solubility of poorly water-soluble drugs and therefore can enhance their absorption. With digestion proceeding and the oil phase breaking down, the surfactant and fatty acids will spread out into the release medium, which causes the drug to release. ${ }^{23,24}$ Surfactants located at the oil droplet surface can interfere with the attachment of the lipase complex to the oil-water interface and inhibit lipolysis of lipids. ${ }^{25-27}$

\section{Conclusion}

A SMEDDS formulation for probucol was developed, and the optimal formulation was as follows: olive oil $(13 \%, w / w)$, Lauroglycol FCC (27\%, w/w), Cremophor EL $(20 \%, w / w)$, Tween-80 (20\%, w/w), and PEG-400 (20\%, $\mathrm{w} / \mathrm{w})$. When diluted with water, probucol-loaded SMEDDS could spontaneously form small particles with average droplet size of about $80 \mathrm{~nm}$. Different media, dilution volume and drug loading seemed to have no effect on droplet size and self-microemulsifying behavior. Dissolution percentages of probucol in SMEDDS in $0.1 \mathrm{M} \mathrm{HCl}$ or in $\mathrm{pH} 7.0$ PBS were significantly higher than that of crude probucol. Relative bioavailability of probucol SMEDDS was dramatically enhanced, approximately 2.15 - and 10.22 -fold that of olive oil solution and suspension, respectively. Our studies illustrated the potential use of SMEDDS for the delivery of hydrophobic compounds, such as probucol.

\section{Acknowledgments}

The work was sponsored by Shanghai Rising-Star Program (10QA1400800), the Scientific Research Foundation for the Returned Overseas Chinese Scholar. This work was also supported by F Hoffmann-La Roche Ltd (Basel, Switzerland).

\section{Disclosure}

No conflicts of interest were reported by the authors of this paper.

\section{Reference}

1. Heel RC, Brogden RN, Speight TM, Avery GS. Probucol: a review of its pharmacological properties and therapeutic use in patients with hypercholesterolemia. Drugs. 1978;15:409-428.

2. Li GP, Yin L, Liu T, et al. Role of probucol in preventing contrastinduced acute kidney injury after coronary interventional procedure. Am J Cardiol. 2009;103:512-514.

3. Sawayama Y, Shimizu C, Maeda N, et al. Effects of probucol and pravastatin on common carotid atherosclerosis in patients with asymptomatic hypercholesterolemia. Fukuoka Atherosclerosis Trial (FAST). J Am Coll Cardiol. 2002;39:610-616.

4. Gershkovich P, Hoffman A. Uptake of lipophilic drugs by plasma derived isolated chylomicrons: Linear correlation with intestinal lymphatic bioavailability. Eur J Pharm Sci. 2005;26:394-404.

5. Physicians' desk reference: Lorelco Tablets. 1995;49:1408-1410.

6. Pouton CW, Porter JH. Formulation of lipid-based delivery systems for oral administration: Materials, methods and strategies. Adv Drug Deliv Rev. 2008;60:625-637.

7. Sagar DM, Shobhona S, Sulabha P, Vandana BP. Development of SMEDDS using natural lipophile: application to $\beta$-artemether delivery. Int J Pharm. 2008;362:179-183.

8. Mette G, Anette M, Jeanet LN, Gitte PP. Bioavailability of seocalcitol II: Development and characterisation of self-microemulsifying drug delivery systems (SMEDDS) for oral administration containing medium and long chain triglycerides. Eur J Pharm Sci. 2006;28:233-242. 
9. Pouton CW. Lipid formulations for oral administration of drugs: non-emulsifying, self-emulsifying and 'self-microemulsifying' drug delivery systems. Eur J Pharm Sci. 2000;11:93-98.

10. Holt DW, Johnston A. Which cyclosporin formulation? Lancet. 1996;348: 1175.

11. Patel AR, Vavia PR. Preparation and in vivo evaluation of SMEDDS (self-microemulsifying drug delivery system) containing fenofibrate. AAPS J. 2007;9:344-352.

12. Qi XD, Cao DY. Preparation and in vivo evaluation of probucol solid dispersion. Chinese Journal of Pharmaceuticals. 2005;36:483-486.

13. Henar O, José LC, Patricia C. Liquid chromatographic method for the simultaneous determination of different lipid-soluble antioxidants in human plasma and low-density lipoproteins. J Chromatogr B Analyt Technol Biomed Life Sci. 2004;803:249-255.

14. Gershanik T, Benita S. Self-dispersing lipid formulations for improving oral absorption of lipophilic drugs. Eur J Pharm Biopharm. 2000;50:179-188.

15. Nielsen FS, Petersen KB, Mullertz A. Bioavailability of probucol from lipid and surfactant based formulations in minipigs: Influence of droplet size and dietary state. Eur J Pharm Biopharm. 2008;69:553-562.

16. Porter CJ, Trevaskis NL, Charman WN. Lipids and lipid-based formulations: Optimizing the oral delivery of lipophilic drugs. Nat Rev Drug Discov. 2007;6:231-248.

17. Pouton CW. Formulation of self-emulsifying drug delivery systems. Adv Drug Deliv Rev. 1997;25:47-58.

18. Humberstone AJ, Charman WN. Lipid based vehicles for the oral delivery of poorly water soluble drugs. Adv Drug Deliv Rev. 1997;25: 103-128.

19. Palin KJ, Wilson CJ. The effect of different oils on the absorption of probucol in the rat. J Pharm Pharmacol. 1984;36:641-643.
20. Yamamoto K, Fukuda N, Shiroi S, et al. Effects of dietary fat levels on the absorption and tissue accumulation of probucol in the rat. Arzneimittelforschung. 1994;44:1059-1062.

21. Brian K, Nordskoga CT, Phana DF. An examination of the factors affecting intestinal lymphatic transport of dietary lipids. Adv Drug Deliv Rev. 2001;50:21-44.

22. Fergal S. Stimulation of triglyceride-rich lipoprotein secretion by polysorbate 80: in vitro and in vivo correlation using Caco-2 cells and a cannulated rat intestinal lymphatic model. Pharm Res. 2004; 21:2320-2326.

23. Hernell O, Staggers JE, Carey MC. Physical-chemical behavior of dietary and biliary lipids during intestinal digestion and absorption. 2 . Phase behaviour and aggregation states of luminal lipids during duodenal fat digestion in healthy adult human beings. Biochemistry. 1990;29:2041-2056.

24. Staggers JE, Hernell O, Stafford RJ, Carey MC. Physical-chemical behaviour of dietary and biliary lipids during intestinal digestion and absorption. 1. Phase behaviour and aggregation states of model lipid systems patterned after aqueous duodenal contents of healthy adult human beings. Biochemistry. 1990;29:2028-2040.

25. Skagerlind $\mathrm{P}$, Jansson M, Hult K. Surfactant interference on lipase catalysed reactions in microemulsions. J Chem Technol Biotechnol. 1992;54:277-282.

26. Canioni P, Julien R, Rathelot J, Sarda L. Inhibition of sheep pancreatic lipase activity against emulsified tributyrin by non-ionic detergents. Biochimie. 1976;58:751-753.

27. Reis P, Holmberg K, Watzke H, Leser ME, Miller R. Lipases at interfaces: A review. Adv Coll Interface Sci. 2009:147-148, 237-250.
International Journal of Nanomedicine

\section{Publish your work in this journal}

The International Journal of Nanomedicine is an international, peerreviewed journal focusing on the application of nanotechnology in diagnostics, therapeutics, and drug delivery systems throughout the biomedical field. This journal is indexed on PubMed Central, MedLine, CAS, SciSearch ${ }^{\circledR}$, Current Contents ${ }^{\circledR} /$ Clinical Medicine,

\section{Dovepress}

Journal Citation Reports/Science Edition, EMBase, Scopus and the Elsevier Bibliographic databases. The manuscript management system is completely online and includes a very quick and fair peer-review system, which is all easy to use. Visit http://www.dovepress.com/ testimonials.php to read real quotes from published authors. 